\title{
Práticas educativas parentais: um estudo comparativo da interação familiar de dois adolescentes distintos ${ }^{1}$
}

\author{
Ana Paula Viezzer Salvador \\ Lidia Natalia Dobrianskyj Weber \\ Universidade Federal do Paraná, Curitiba
}

\begin{abstract}
RESUMO
No presente estudo objetivou-se investigar e comparar, de forma qualitativa, as práticas parentais recebidas por dois adolescentes. Cada adolescente (de 16 e 17 anos, ambos do sexo masculino, provenientes do mesmo nível socioeducacional, foi selecionado de uma instituição diferente: um pertencia a uma ONG que patrocina os estudos particulares de alunos carentes com alto desempenho acadêmico e o outro estava detido provisoriamente à espera de julgamento por cometer ato infracional. Com autorização das instituições, foram realizadas entrevistas individuais, baseadas nas Escalas de Qualidade na Interação Familiar (Weber, Viezzer e Brandenburg, 2003). As categorias investigadas foram: relacionamento afetivo, reforçamento, envolvimento, regras e monitoria, comunicação, punição, auto-estima e envolvimento com pares desviantes. $\mathrm{O}$ relato do adolescente detido revelou pais com baixo envolvimento e demonstração de afeto; uso inadequado de reforçamento positivo, ausência de regras e monitoria, comunicação coercitiva, punições extremamente exageradas, além de envolvimento com pares desviantes. Já no relato do outro adolescente foi possível perceber pais com maior envolvimento e demonstração de amor, regras claras, uso adequado de reforçamento positivo, comunicação positiva, punições brandas e consistentes e o não-envolvimento do participante com pares desviantes. Pôde-se concluir que houve predominância de práticas parentais coercitivas na família do adolescente com comportamentos anti-sociais, e predominância de práticas parentais nãocoercitivas na família do adolescente da ONG.
\end{abstract}

Palavras-chave: interações familiares; práticas parentais; relação pais-filhos.

\section{ABSTRACT \\ Parenting practices: a comparative study about the family interaction of two distinct adolescents}

The present study aimed to investigate and compare, through a qualitative approach, the parenting practices received by two adolescents. Each adolescent (16 and 17 years old, both male) was selected in a different institution: one was recruited in a NGO that sponsors the study in private schools for low income students who demonstrate high academic achievement; and the other was under provisory detention waiting for the judgement of an infraction. With the authorization of both institutions, individual interviews were conducted, based on the Scale of Family Interaction's Quality (Weber, Viezzer, Brandenburg, 2003). The investigated categories were: affection, reinforcement, involvement, rules and monitoring, communication, punishment, self-esteem and deviant partner involvement. In the story of the adolescent under provisory detention it was found little involvement and demonstration of love; inadequate use of positive reinforcement, rules with little monitoring, coercive communication, extremely exaggerated punishment and deviant partner involvement. In the story of the other participant it was found a greater involvement and love demonstration, clear rules, adequate use of positive reinforcement, positive communication, use of mild and consistent punishment, and no deviant partner involvement. It is possible to conclude that coercive parenting practices predominated on the family of the adolescent with antisocial behavior, and the non-coercive practices predominated on the family of the adolescent from the NGO.

Keywords: family interactions; parenting practices; parents-son relationship. 
A figura dos pais, como primeiro núcleo social da criança, tem grande influência no processo de desenvolvimento social, cognitivo e psicológico de uma criança. Mais tarde, outras relações sociais também trazem contribuições para o desenvolvimento de crianças e adolescentes, mas é a relação com os pais que constitui a base referencial de todas as outras, por serem eles os responsáveis em transmitir as primeiras informações e interpretações sobre o mundo. A relação entre pais e filhos pode ser estudada através das práticas educativas parentais.

As práticas parentais correspondem a comportamentos definidos por conteúdos específicos e por objetivos de socialização; diferentes práticas parentais podem ser equivalentes para um mesmo efeito no filho. As práticas são estratégias com o objetivo de suprimir comportamentos considerados inadequados ou de incentivar a ocorrência de comportamentos adequados (Alvarenga, 2001). Existem diversas pesquisas comprovando que diferentes práticas estão associadas a diferentes aspectos de desenvolvimento dos filhos (Belsky, Hsieh \& Crnic,1998; Dishion, Patterson, Stoolmiller \& Skinner, 1991; Kochanska \& Aksan, 1995; Krevans \& Gibbs,1996; Reid, Patterson \& Snyder, 2002; Schaffer \& Crook, 1980).

Alvarenga (2001) fez uma interessante distinção entre práticas educativas parentais não-coercitivas e coercitivas: as não-coercitivas são aquelas que basicamente fazem uso de reforçadores positivos e regras; já as coercitivas são aquelas que fazem uso de estímulos aversivos. Dentre as práticas parentais nãocoercitivas podem ser considerados o afeto, envolvimento, reforçamento, regras e comunicação (diálogos e orientações). E dentre as práticas coercitivas, podese dar grande destaque ao uso da punição, seja esta verbal, física ou a privação.

\section{Práticas parentais não-coercitivas}

Quando se fala em afeto e envolvimento na relação entre pais e filhos, uma questão muito importante a ser considerada é que uma criança somente se sentirá amada pelos seus pais se eles demonstrarem isso. Para Skinner (1991, p. 17), "ao demonstrar que estamos contentes quando uma pessoa se une a nós, nós reforçamos a união (...) não é o nosso comportamento, mas o comportamento daquele que amamos que é reforçado". O amor é um sentimento, e como qualquer outro comportamento privado, é de difícil acesso quando não é verbalizado ou demonstrado com comportamentos públicos. "O mundo não reage a nossos pensamentos e sentimentos, mas àquilo que vê e ouve fazendo" (Sidman, 2001, p.48). Além disso, Sidman enfatiza a idéia de que as crianças não precisam fazer algo especial para obter o amor e proteção de seus pais, ou seja, para que as crianças se sintam seguras, elas precisam ter certeza de que o amor de seus pais ainda estará disponível mesmo que não consigam enfrentar uma contingência com êxito.

Alguns autores afirmam que quando o filho se sente amado pelos seus pais, torna-se muito mais fácil apresentar regras, pois ele compreende melhor os valores morais de seus pais (Grusec, Goodnow \& Kuczynski, 2000; Severe, 2000; Weber, 2005). Quando o clima é caloroso e acolhedor as crianças aceitam mais facilmente as orientações e punições dos pais por saberem que eles estão agindo com amor e preocupação (Severe, 2000). Para Cavell (2000), disciplinar ou controlar a criança em meio a um relacionamento negativo é mais difícil, pois a criança não faz a distinção necessária entre comportamentos proibidos e permitidos.

Muitas pesquisas têm demonstrado o quanto o aspecto afetivo influencia no desenvolvimento social e psicológico dos filhos. Simons, Lin e Gordon (1998) pesquisaram que o baixo apoio e envolvimento dos pais foram associados com delinquiência e uso de drogas na adolescência. Stormshak, Bierman, McMahon e Lengua (2000) encontraram dados semelhantes: pais com baixo nível de envolvimento afetivo possuem filhos com elevado nível de comportamentos de contrariedade. Chen, Chen, Liu e Wang (2002) relataram que a falta de afeto e de responsividade dos pais pode reforçar comportamentos desviantes e de hostilidade nas interações com outras crianças. Chen e cols. (2002) concluíram em sua pesquisa que o afeto parental é muito importante no desenvolvimento de comportamentos pró-sociais da criança.

Grande importância deve ser dada ao uso de reforçadores positivos. Segundo Sidman (2001), o reforçamento positivo é a principal técnica não-coercitiva de controle de comportamento. O reforçador possui duas características que o definem: ele segue uma ação e ele torna mais provável que a ação se repita. Sendo assim, os reforçadores positivos fortalecem as ações que o tenham produzido (Sidman, 2001).

O reforço positivo pode ser utilizado pelos pais para incentivar e fortalecer comportamentos desejáveis em suas crianças, como também para desestimular e substituir os indesejáveis (Severe, 2000; Sidman, 2001; Weber, 2005). Além de ser uma excelente técnica de controle e modelagem de comportamento, o reforço positivo proporciona inúmeros efeitos positivos no desenvolvimento das crianças.

Para Severe (2000), o reforço positivo constrói a auto-estima da criança, a encoraja a superar problemas, medo e estresse. Além disso, aumenta a motiva- 
ção, desenvolve responsabilidade, dá autoconfiança, e alimenta a sensação de sucesso. Para Sidman (2001), o reforço positivo produz sentimentos de satisfação, pois proporcionam às pessoas algo que elas desejam. Sidman (2001, p. 251) ainda complementa dizendo que os pais que dão oportunidades para o recebimento de reforço positivo, têm filhos mais felizes e competentes, e que "as famílias que praticam reforçamento positivo desfrutam de um benefício adicional: raramente surgem motivos para punição".

Pesquisas mostram o efeito do reforço no comportamento das crianças, como por exemplo, o aumento no número de tarefas domésticas realizadas ao receber fichas como reforço (Gomes, 1981) e melhora nas habilidades escolares e relações pró-sociais (Patterson \& Stouthammer-Loeber, 1984). O reforço recebido em casa também tem um efeito que se estende para outras esferas da vida da criança. As crianças que recebem mensagens positivas de seus pais elogiam mais os outros (Webster-Stratton \& Herbert, 1994). Pesquisas demonstram que as crianças que elogiam os outros possuem mais colegas na escola e recebem mais elogios, o que contribui para aumentar ainda mais sua auto-estima e bem-estar (Webster-Stratton \& Herbert, 1994).

Uma importante ressalva deve ser feita, como as pessoas reforçam comportamentos umas das outras sem perceber, muitas vezes podem reforçar comportamentos inadequados para o contexto cultural em que vivem. Pais que dão atenção para os filhos somente quando eles apresentam problemas de comportamento estão reforçando os comportamentos inadequados (Sidman, 2001). Se existem comportamentos inadequados, como agressividade, no repertório comportamental das crianças é porque estão sendo mantidos por algum reforçador. Nestes casos, para diminuir a ocorrência de comportamentos inadequados, é necessário diminuir o reforço e aumentar o custo desses comportamentos (Cavell, 2000).

As regras são também especialmente importantes para o desenvolvimento das crianças, pois como sujeitos verbais, grande parte de seus comportamentos são adquiridos através de descrições verbais, apresentadas como regras, e que especificam as contingências do ambiente da criança. (Castanheira, 2001). Quando as regras são justas e racionais, a criança aprende facilmente em que condições certos comportamentos devem ou não ser emitidos, além de saber porque razões poderá ser reforçada ou punida (Sousa \& Baptista, 2001).

Qualquer criança precisa desenvolver o sentido do que é permitido e do que é proibido. Além disso, den- tro da gama de comportamentos que são proibidos, ela precisa aprender quais são os menos aceitáveis. Se ela não consegue perceber quais são os comportamentos que ela precisa prestar mais atenção para suprimir, a probabilidade será menor de ela realizar discriminações morais (Cavell, 2000).

Para Matos (2001), o seguimento de regras deve ser reforçado pelos pais, pois uma criança que aprende a obedecer, sabe respeitar limites, e muitas condutas indesejáveis podem ser evitadas. Além do reforço necessário para o cumprimento de regras, é necessário que elas sejam transmitidas com uma linguagem plenamente compreensível (Cavell, 2000; Matos, 2001; Sousa \& Baptista, 2001). Matos (2001) enfatiza que o cumprimento de regras também depende da habilidade ou capacidade dos pais em monitorar a criança, da habilidade dos pais em cumprir com as conseqüêencias previstas, como também da confiança que a criança deposita nos pais.

Ainda como prática não-coercitiva, pode-se citar a comunicação. A comunicação está presente na vida das crianças, como falantes ou ouvintes, e enquanto ouvintes, a comunicação pode ser fonte de informações, orientações, aprendizados, reforçamentos, determinação de regras, entre outros (pode ser fonte de punições, porém isto a caracterizaria como prática coercitiva). O comportamento verbal é de extrema importância para a interação entre os seres humanos. É importante lembrar que os pais que criam filhos mais competentes e seguros (os pais participativos) são aqueles que incentivem o diálogo, compartilham com a criança o raciocínio por detrás da forma como eles agem e solicitam suas objeções quando ela se recusa a concordar (Baumrind, 1966).

Os pais também precisam ser bons ouvintes, uma vez que o comportamento verbal de qualquer pessoa é mantido pelo ambiente verbal ou cultural, quando os pais ouvem seus filhos estão reforçando e mantendo a comunicação expressa por seus filhos. Na medida em que os pais ouvem e dão importância ao que a criança fala, estão dando um modelo, ou seja, provavelmente as crianças aprenderão a ouvi-los quando necessário. Além disso, a comunicação positiva aparece como fator protetivo em diversas pesquisas sobre relação pais e filhos (Kaplow, Curran \& Dodge, 2002; Kelly, Comello \& Hunn, 2002; Kafka \& London, 1991).

\section{Práticas parentais coercitivas}

As práticas coercitivas, que se referem ao controle por meio de estímulos aversivos, são aplicadas pelos pais sob forma de punições verbais, físicas ou de privação. Não existe punição sem coerção, e enquanto 
coerção, é preciso ressaltar os perigos envolvidos nesta classe de comportamentos. A punição é a forma de controle do comportamento humano mais comum na vida moderna (Skinner, 1998; Todorov, 2001). "Uma ação punida pára imediatamente, ajudando a criar a ilusão de que a punição realmente cumpre sua tarefa" (Sidman, 2001, p. 232; Skinner, 1998). Porém as consequiências da punição (subprodutos e efeitos colaterais) cancelam facilmente os benefícios que poderiam trazer.

Skinner (1998) questionou o uso da punição. Na verdade ele mostrou, por meio de experimentos com animais, que ela não funciona a longo prazo e traz efeitos maléficos. A punição gera subprodutos muito negativos para aqueles que a vivenciam, tais como "violência, agressão, opressão, depressão, inflexibilidade emocional e intelectual, autodestruição e destruição dos demais, ódio, doenças e estado geral de infelicidade" (Sidman, 2001, p. 248). Além disso, para Sidman, os efeitos colaterais não oferecem caminhos alternativos de ação para a criança, dificultando a sua adaptação construtiva na sociedade. Um dos efeitos colaterais é o fato de que as pessoas que utilizam punições tornam-se elas próprias punidores condicionados, ou seja, a simples presença do agente punidor pode se transformar em punição. Assim, pais que criam lares coercitivos, com o uso freqüente de punições, podem ter filhos que os temem, odeiam e se esquivam deles (Sidman, 2001).

Outro grave efeito colateral é o condicionamento de fuga e esquiva (Catania, 1999; Sidman, 2001; Sousa \& Baptista, 2001). O estímulo aversivo utilizado pelos pais pode facilmente se tornar um reforçador negativo (Catania, 1999). Sendo assim, com o uso da punição, os pais ensinam e mantêm comportamentos com os quais a criança possa fugir ou se esquivar do evento aversivo que eles apresentam, e até mesmo dos próprios pais.

Muitos autores alertam para os efeitos negativos da punição. Para Severe (2000), as punições que são utilizadas para constranger, humilhar ou depreciar as crianças, podem gerar sentimentos doentios. Quando os pais rotulam e depreciam a criança, estão contribuindo para a formulação de auto-regras negativas. Auto-regras inadequadas podem influenciar nos estados de depressão e identificam o desamparo aprendido (Castanheira, 2001).

As punições chamam a atenção para o comportamento inadequado, geram raiva, sentimentos de fracasso, enfraquecem a auto-estima e autoconfiança da criança e ensinam o medo (Severe, 2000). Pesquisas mostram que a exposição freqüente à punição física aumenta o risco de o adolescente se envolver em brigas (Simons \& cols., 1998). Problemas comportamentais dos filhos (hiperatividade e agressividade e contrariedade) podem estar relacionados com práticas parentais que incluem interações punitivas (Stormshak \& cols., 2000).

Todos os efeitos colaterais e subprodutos decorrentes de uma educação coercitiva, como já citados, são também aplicados à punição física. Porém há um agravante na punição física: ela ensina que o comportamento agressivo é válido, que é uma atitude normal que pode ser utilizada para se resolver problemas (Weber \& cols., 2003b). A pesquisa de Weber e cols. (2003b) mostrou mais um agravante da punição física: ela é um fator de risco para o abuso físico. Estas autoras constataram que quando o agente punidor não percebe os resultados esperados para corrigir os comportamentos indesejáveis de seus filhos, eles tendem a bater com maior frequiência e intensidade.

Apesar de tantos efeitos nocivos advindos da punição, a maioria dos pais se depara com situações nas quais a punição é inevitável. Por isso é necessário orientar as famílias sobre formas de aplicar punições que não acarretem em tantos prejuízos. O principal é que "as crianças devem ser ensinadas que certos comportamentos simplesmente não são permitidos" (Cavell, 2000 , p. 163). Este aprendizado ocorre muito mais facilmente, e sem prejuízos à família, quando se cria um contexto não-coercitivo com uso intenso de reforçadores positivos, e assim, a punição torna-se desnecessária, ou pelo menos, rara.

O objetivo da presente pesquisa foi o de realizar um estudo qualitativo para investigar e comparar as práticas parentais recebidas por dois adolescentes com comportamentos bastante diferenciados (um selecionado por uma ONG que financia estudos em escolas particulares para alunos carentes com excelentes notas e outro detido por cometer ato infracional). As práticas parentais foram acessadas por meio do relato dos adolescentes, portanto trabalhou-se com a percepção destes jovens sobre a forma como foram educados por seus pais.

\section{MÉTODO}

\section{Participantes}

Participaram desta pesquisa dois adolescentes, ambos do sexo masculino, e oriundos de famílias de classe socioeconômica baixa. A seguir, a identificação e a configuração familiar dos dois participantes (os nomes dos adolescentes aqui utilizados são fictícios e os dados referem-se à época em foram realizadas as 
entrevistas): RAFAEL: 16 anos de idade, selecionado pelo Instituto Bom Aluno do Brasil ${ }^{2}$, concluiu o $2^{\circ}$ ano do ensino médio em escola particular (com financiamento do Instituto). Foi selecionado pelo Instituto por apresentar desempenho escolar satisfatório (notas sempre acima de 7,0), freqüência nas aulas, grande interesse e comprometimento com os estudos e comportamento disciplinado. Morava com pai e mãe (casados), tinha um irmão de 14 anos e outro de 7 meses de idade. PAULO: 17 anos de idade, detido provisoriamente no $\mathrm{SAS}^{3}$ por ter cometido ato infracional, e estava à espera de julgamento. Reincidente em cometer infrações, já esteve preso por um período aproximado de um ano e sete meses, por se envolver com roubo de carro e sequiestro relâmpago. $\mathrm{Na}$ época das entrevistas, estava à espera de julgamento por crime de homicídio. Estudou até a $8^{a}$ série do ensino fundamental, em escola pública, e fez alguns cursos durante o período em que esteve preso. Paulo já reprovou algumas vezes na escola, indicando desempenho escolar insatisfatório. Morava com sua mãe e alguns de seus irmãos antes de ser detido. Seu pai faleceu em 1997 de diabetes. Paulo era o $4^{\circ}$ filho de uma prole de sete irmãos, mas um irmão mais velho foi assassinado logo depois da morte do pai. Paulo morou com sua namorada por um período aproximado de um ano, com quem teve um filho.

\section{Instrumentos}

Foi utilizado o instrumento "Escalas de Qualidade de Interação Familiar - EQIF" (Weber, Viezzer \& Brandenburg, 2003a) como roteiro para as entrevistas semi-estruturadas, ou seja, os adolescentes respondiam as questões do EQIF e a outras perguntas que tinham o objetivo de aprofundar o assunto com os participantes, na medida em que eles se mostravam disponíveis para isto. $\mathrm{O}$ instrumento EQIF contém 50 questões divididas em 10 escalas: relacionamento afetivo e reforçamento, envolvimento, regras e monitoria, modelo, sentimento dos filhos, comunicação negativa, comunicação positiva dos filhos, punição corporal, clima conjugal positivo e clima conjugal negativo. Porém, foram utilizadas nas entrevistas apenas as escalas que avaliam práticas parentais, ou seja, as escalas de modelo, sentimento dos filhos, clima conjugal positivo e negativo não foram utilizadas.

\section{Procedimentos}

Primeiramente, foi feito o contato com as instituições (Instituto Bom Aluno do Brasil e SAS), as quais autorizaram a realização da pesquisa. A escolha dos participantes foi realizada pelas instituições, sem qualquer conhecimento prévio das pesquisadoras. A única recomendação dada às instituições foi de que os participantes deveriam ter idades aproximadas (entre 16 e 17 anos), ambos do sexo masculino e que fossem pertencentes a famílias biparentais. Desta forma, foi possível garantir alguns pontos em comum entre os dois adolescentes (idade, sexo, classe socioeconômica e estrutura familiar), facilitando a comparação. Depois da escolha dos participantes, foram realizadas as entrevistas semi-estruturadas (quatro entrevistas com Rafael e cinco com Paulo). Todas as entrevistas foram realizadas individualmente, com total privacidade, utilizando o espaço físico das próprias instituições. $\mathrm{Na}$ primeira entrevista realizada com os adolescentes objetivou-se estabelecer um bom rapport, portanto a entrevistadora não abordou temas relativos à interação familiar. Para Paulo, houve a necessidade de uma segunda entrevista para estabelecer um bom vínculo, e para confirmar informações confusas dadas na primeira entrevista. Portanto somente em três entrevistas realizadas com cada um dos adolescentes é que foram abordados os temas relativos às práticas parentais. Vale ressaltar que as entrevistas foram realizadas apenas com os adolescentes, não havendo qualquer contato com os familiares destes.

\section{Análise de dados}

Foi realizada uma análise qualitativa das entrevistas realizadas, comparando o relato dos dois participantes. As categorias (ou temas) de análise foram escolhidas a priori e correspondiam às escalas do instrumento EQIF (relacionamento afetivo e reforçamento, envolvimento, regras e monitoria, comunicação negativa, comunicação positiva dos filhos e punição corporal). Na apresentação dos resultados foram agrupadas algumas categorias: relacionamento afetivo e reforçamento com envolvimento; comunicação negativa com comunicação positiva dos filhos. Além das categorias a priori, também foi feita uma análise sobre auto-estima e envolvimento com pares desviantes, que foram temas não selecionados previamente no roteiro das entrevistas, mas que surgiram no relato dos participantes.

\section{RESULTADOS E DISCUSSÃO}

Os resultados estão agrupados por temas, como já indicados no método. Para a apresentação e análise dos resultados, foram selecionadas as frases relatadas pelos adolescentes referentes a cada um dos temas. Estas frases estão apresentadas em tabelas, a fim de facilitar a visualização e comparação dos relatos. 


\section{Relacionamento afetivo, envolvimento e reforçamento}

Sobre estes temas foi possível verificar frases dos adolescentes que se referem principalmente sobre como os pais os ajudavam, demonstravam amor e orgulho, bem como sobre o uso de reforçamento positivo. Tais dados podem ser visualizados na Tabela 1.

Tabela 1. Apresentação das frases relatadas por Rafael e Paulo, em relação aos temas relacionamento afetivo, envolvimento e reforçamento

\begin{tabular}{|c|c|}
\hline Rafael & Paulo \\
\hline $\begin{array}{l}\text { 1- "Eles procuram saber do que se trata, se eles podem ou não } \\
\text { ajudar, às vezes eles não podem me ajudar. E se eles não } \\
\text { tem possibilidades, eles procuram alguma outra pessoa que } \\
\text { possa me ajudar." } \\
\text { 2- "Sempre que eles vêem que eu estou meio desanimado, eles } \\
\text { perguntam o que está acontecendo e se eles podem me aju- } \\
\text { dar em alguma coisa." } \\
\text { 3- "Às vezes eu ia mal em alguma prova, ficava triste, às vezes } \\
\text { eu chorava, pensava que não ia conseguir, mas eles falavam } \\
\text { que não precisava chorar, que ia ter uma outra prova e que } \\
\text { eu ia conseguir recuperar. Eu fazia a prova e recuperava." } \\
\text { 4- "Eles fazem elogios quando eu faço alguma coisa legal, ou que } \\
\text { eles gostam, acho que eles estão demonstrando amor." } \\
\text { 5- "Às vezes quando eu chego da escola meu pai fala: ah, o } \\
\text { meu amor chegou. (...) O meu pai faz isso quase todo dia, é } \\
\text { meio que corriqueiro, mas eu vejo que é porque ele sente } \\
\text { amor por mim." } \\
\text { 6- "O meu pai costuma falar que eu sou bastante estudioso, que } \\
\text { quando eu não estou em casa eu estou estudando, sei lá, } \\
\text { ele acha que isso é bom. Eu vejo que ele fala de um jeito le- } \\
\text { gal." } \\
\text { 7- "Ele gosta de elogiar eu que estou estudando." } \\
\text { 8- "Eles falam que eu estou bem, quando eu vou mal eles meio } \\
\text { que elogiam, falam que eu posso melhorar da próxima vez, } \\
\text { às vezes fazem um carinho, essas coisas." } \\
\text { 9- O tipo de carinho que eles normalmente fazem "é elogio, na } \\
\text { maioria da vezes é elogio". }\end{array}$ & $\begin{array}{l}\text { 1- "O meu pai ajudava só quando tinha problema que a minha } \\
\text { mãe não sabia, tipo matemática, que ela estudou só até a } \\
\text { quarta série, mas ela ajudava direto, porque ela era inteli- } \\
\text { gente. E meu pai já era experiente em matemática, daí } \\
\text { quando tinha problema de matemática ele ajudava eu, mas } \\
\text { era difícil." } \\
\text { 2- "Se ele (o pai) via que eu estava meio triste, levava eu pra } \\
\text { passear." } \\
\text { 3- "Minha mãe demonstrava direto, fazia carinho e abraçava eu, } \\
\text { passava a mão na minha cabeça, mas meu pai não demos- } \\
\text { trava muito." } \\
\text { 4- "Minha mãe sim, só pelo jeito dela falar, falava de "boca } \\
\text { cheia' do orgulho que tinha de mim, mas o meu pai não. O } \\
\text { meu pai nunca vi." } \\
\text { 5- "Quando eu era pequeno meu pai se preocupava com a } \\
\text { gente quando estava doente só, a mãe da gente se preocu- } \\
\text { pa toda hora. Sai do portão pra fora, ela já fica preocupada." } \\
\text { 6- "Ela falava bem de mim para os vizinhos e parentes dela, pra } \\
\text { eles ela falava bem. Para os outros eu e meu irmão mais } \\
\text { velho era os mais ruins da família, e pra ela não, pra ela nós } \\
\text { era os mais sossegados." } \\
\text { 7- "Minha mãe me ajudava, ela ia no colégio, conversava com a } \\
\text { diretora, e pro meu pai não brigar comigo, minha mãe dizia } \\
\text { que foi o outro piá que começou a briga." } \\
\text { 8- "Minha mãe ficava mais alegre quando nós ia na igreja. } \\
\text { Quando a gente saía, quando não aprontava nada e ficava } \\
\text { quieto, eles ficavam alegres com a gente. De passear na } \\
\text { casa dos parentes eles ficavam alegres." } \\
\text { 9- "Minha mãe ficava alegre direto quando nós fazia a lição tudo } \\
\text { certinho." }\end{array}$ \\
\hline
\end{tabular}

Observando as frases apresentadas na Tabela 1, é possível verificar como o envolvimento e afeto estavam mais presentes na família de Rafael. Este adolescente relatou comportamentos de seus pais que parecem demonstrar um envolvimento mais profundo e intenso, ou seja, seus pais o incentivavam, demonstravam orgulho pelo fato de terem um filho estudioso, demonstravam amor e apoio mesmo quando Rafael não obtinha sucesso (no caso das provas) e verbalizavam explicitamente seu amor por Rafael por meio de elogios e comentários cotidianos. Muitos autores têm enfatizado o quanto estas práticas parentais utilizadas pelos pais de Rafael (observadas em seu discurso) contribuem para um desenvolvimento psicológico e emocional saudável, como também para o desenvolvimento de comportamentos pró-sociais (Chen \& cols., 2002; Severe, 2000; Sidman, 2001).
As frases selecionadas no discurso de Paulo mostram uma diferença essencial: ele falou de seu pai e de sua mãe separadamente, pois os dois agiam de forma diferente. Relatou que a sua mãe o ajudava nas lições de casa, fazia carinhos, demostrava orgulho e se preocupava freqüentemente, enquanto que seu pai não demostrava nada disso ou se o fazia era bem pouco freqüente. Paulo fez um comentário sobre seu pai, afirmando que o levava para passear quando percebia que Paulo estava triste, o que parece ser uma aproximação e demonstração de afeto. Porém isto pode ser discutível, pois Paulo não relatou nenhum comportamento de seu pai que fosse de diálogo, incentivo ou carinho, portanto o que este adolescente relatou pode ser entendido como um envolvimento bastante superficial ou até mesmo ausente. Alguns pesquisadores mostraram que a falta de amor e envolvimento dos 
pais pode levar à delinqüência e uso de drogas (Simons \& cols., 1998; Stormshak \& cols., 2000), sendo assim, é possível discutir que a falta de afeto e envolvimento do pai de Paulo pode, de alguma forma, ter contribuído para a sua condição atual de delinqüência e criminalidade.

Através do relato de Rafael, foi possível perceber que seus pais faziam bastante uso de reforçadores, e mais importante que isso, faziam uso de reforçadores sociais como atenção, elogios e carinhos. Isto certamente contribuiu para fortalecer comportamentos desejáveis, como por exemplo, boas habilidades escolares e relações pró-sociais, auto-estima elevada e responsabilidade (Patterson \& Stouthammer-Loeber, 1984; Severe, 2000; Sidman, 2001). No discurso de Paulo também foi possível observar o uso de reforçadores positivos como a atenção e carinho, porém duas considerações devem ser feitas sobre seu relato. Primeiramente, Paulo se refere somente a sua mãe, ou seja, em nenhum momento mencionou o uso de reforçamento positivo por seu pai, o que pode significar que seu pai não utilizava este tipo de controle. E em segundo lugar, percebe-se (nas frases 6 e 7 de Paulo, na Tabela 1) que provavelmente sua mãe fazia uso incorreto de reforçadores positivos. Ao defender seu filho, escondendo de seu pai e de outras pessoas seus comportamentos inadequados (como briga na escola, por exemplo), a mãe de Paulo reforçava tais comportamentos. Pode-se levantar a hipótese de que comportamentos indesejáveis e agressivos apresentados por Paulo em sua infância (principalmente na escola) eram reforçados e mantidos por sua mãe, que lhe dava atenção e proteção em tais situações, o que de alguma forma pode ter contribuído na modelagem de comportamentos anti-sociais de Paulo.

\section{Regras}

Quanto ao tema relativo às regras, os adolescentes mencionaram principalmente que obrigações eles deviam cumprir em casa, o que acontecia se eles não cumprissem e também sobre as regras que deviam seguir para sair com amigos. Estes aspectos podem ser observados nas frases da Tabela 2.

Tabela 2. Apresentação das frases relatadas por Rafael e Paulo, em relação ao tema regras

\begin{tabular}{|c|c|}
\hline Rafael & Paulo \\
\hline $\begin{array}{l}\text { 1- "Eu ajudo minha mãe a limpar a casa, lavar a louça do almo- } \\
\text { ço, faço o que ela pede." } \\
\text { 2- "Mas eles nem vêem o que eu fiz, sei lá, eles acham que eu } \\
\text { já fiz ou que eu vou fazer. Mas às vezes quando eu esqueço, } \\
\text { eles pedem pra mim: oh, vai fazer, que você esqueceu." } \\
\text { 3- "Se eu vou sair com alguém meu pai pergunta com quem } \\
\text { que eu vou, que horas que eu vou voltar, às vezes pede o } \\
\text { telefone da casa de algum amigo que ele possa ligar, esti- } \\
\text { pula horário pra eu voltar pra casa." }\end{array}$ & $\begin{array}{l}\text { 1- "Tinha obrigação de lavar louça, obrigação do dever de casa, } \\
\text { um monte de coisa. Ȧs vezes revezava, tinha que limpar o } \\
\text { chão, tirar o pó, arrumar o quarto." } \\
\text { 2- "Se não tivesse feito alguma coisa a minha mãe já brigava, } \\
\text { passava o dedo pra ver se tinha pó, ela não gostava de ver } \\
\text { um pozinho." } \\
\text { 3- "Na casa dos amigos que ele não queria que eu fosse, eu } \\
\text { saltava. Daí eu ia escondido." }\end{array}$ \\
\hline
\end{tabular}

Os dois adolescentes falaram sobre as obrigações que precisavam cumprir em casa, e em seus relatos estas pareciam ser muito semelhantes, como no caso das tarefas domésticas (lavar louça e limpar a casa). A diferença sutil aparece na forma como cada um falou sobre isso: Rafael disse que "ele ajuda" sua mãe nas coisas que ela pedia; enquanto que Paulo se referiu apenas às obrigações que precisava cumprir. Isto pode significar uma menor motivação, por parte de Paulo, para ajudar seus pais. Enquanto que a forma como Rafael relatou pode estar revelando uma relação de respeito com seus pais e de maior motivação para ajudá-los.

Ao analisar as frases 2 e 3 dos dois adolescentes (na Tabela 2), novamente percebe-se que a relação de Rafael com seus pais era permeada de confiança e tolerância. Provavelmente havia um controle por re- gras bastante grande, mas quando a pessoa que dita as regras é alguém de confiança, as chances de que as regras sejam de fato cumpridas é bem maior (Matos, 2001). Enquanto que na relação de Paulo com seus pais foi possível perceber um controle mais coercitivo (a mãe já brigava) e também a falta de monitoria de seus pais (não sabiam que Paulo saía escondido). Além de ele ter dito que sua mãe logo brigava quando algo não tinha sido feito, Paulo também relatou que quando seu pai não permitia que ele saísse, então saía escondido. Sendo assim, se Paulo não os obedecia ou as regras não estavam devidamente esclarecidas (o que não foi possível observar em seu relato), ou o controle coercitivo era muito intenso, podendo gerar esquiva (sair escondido e fazer coisas sem que seus pais soubessem provavelmente eram comportamentos para se esquivar do controle coercitivo dos pais). A 
falta de monitoria dos pais de Paulo também pode ter contribuído para a sua não obediência, pois segundo Matos (2001), a capacidade em monitorar comportamentos é essencial para o cumprimento de regras.

\section{Comunicação}

A comunicação permeia muitas outras categorias de práticas parentais apresentadas neste trabalho, ou seja, a comunicação pode ser facilitadora da aplicação de regras, reforço positivo, demonstração de afeto e aplicação de punições. E por isso poderia ser avaliada de forma bastante ampla. Porém, de forma mais restrita, será apresentado e discutido aqui o que os adolescentes relataram sobre: quanto eles perguntam coisas (para tirar dúvidas) e contam sobre suas próprias vidas para seus pais; e quanto seus pais ouvem e respeitam o que é dito por seus filhos. Estes relatos estão na Tabela 3.

Tabela 3: Apresentação das frases relatadas por Rafael e Paulo, em relação ao tema comunicação

\begin{tabular}{|c|c|}
\hline Rafael & Paulo \\
\hline $\begin{array}{l}\text { 1- "Meu pai é mais duro, assim, quando você faz alguma coisa } \\
\text { errada, ele às vezes não quer saber, porque ele acha que } \\
\text { ele está certo, minha mãe dá mais atenção. Ela quer ouvir os } \\
\text { dois lados. Meu pai já é mais severo, ele acha que ele está } \\
\text { certo. Agora, assim, acho que não tenho muitos problemas } \\
\text { com meu pai." } \\
\text { 2- "Com meu pai é mais difícil conversar com ele." } \\
\text { 3- "Eles falam o suficiente para esclarecer o que eu perguntei." } \\
\text { 4- "Eles sempre falam comigo, se eu faço alguma coisa de ruim } \\
\text { para alguém eles me entrevistam. Primeiro perguntam por- } \\
\text { que eu fiz, o que eu tinha na cabeça para fazer aquilo, se era } \\
\text { ruim eles falam que eu não deveria ter feito, daí eles falam } \\
\text { por que não. Eles sempre vinham com vontade de conversar." } \\
\text { 5- "Ela escuta, eu chego para falar, ela pega e compreende o } \\
\text { que eu falei, meu pai é mais quieto." } \\
\text { 6- "Sempre conto, igual pros dois. Eu conto porque eu acho que } \\
\text { estou bem e eles devem saber disso, porque eles devem } \\
\text { estar sabendo que estou fazendo uma coisa legal." } \\
\text { 7- "Ameaça eles quase nunca fazem." } \\
\text { 8- "Acredito que a maioria das críticas são construtivas, para eu } \\
\text { melhorar o que eu fiz ou se fiz alguma coisa ruim para não } \\
\text { fazer mais." }\end{array}$ & $\begin{array}{l}\text { 1- "Com a minha mãe todo dia conversava, mas com meu pai } \\
\text { eu apanhava sempre, eu ia fazer uma coisinha já apanhava." } \\
\text { 2- "Eu não contava nada pra ele. É claro, eu tinha medo de } \\
\text { apanhar quando chegava em casa." } \\
\text { 3- "Dúvidas do dever de casa, quando eu chegava da escola, } \\
\text { tinha muita dúvida da escola, ficava com medo de perguntar } \\
\text { pro meu pai, perguntava mais pra minha mãe, e minha mãe } \\
\text { me explicava." } \\
\text { 4- "Quando eu pedia pra ele pra sair de carro junto, e ele gritava } \\
\text { e brigava." } \\
\text { 5- "Ele falava um monte de palavrão. Um pai xingando um filho, } \\
\text { né cara, a gente ficava... chorava. Ficava triste." } \\
\text { 6- "Meu pai implicava com qualquer coisa." } \\
\text { 7- "Ele ameaçava bater, deixar de castigo." } \\
\text { 8- "Mas meu pai falava um monte, e eu tinha que ficar escutan- } \\
\text { do aqueles desaforos." }\end{array}$ \\
\hline
\end{tabular}

Ao observar as oito frases de Rafael (apresentadas na Tabela 3), é possível constatar que, apesar de seu pai ser mais duro, fechado e não conversar muito, Rafael e seus pais mantinham uma comunicação bastante positiva. Rafael relatou ter iniciativa de contar sobre sua vida e de perguntar sobre coisas que tinha dúvida para seus pais. E em contrapartida, seus pais pareciam ouvir e responder aquilo que sabiam. Além disso, quando Rafael não se comportava como deveria, seus pais procuravam conversar antes de tomar atitudes mais drásticas, como deixar de castigo ou bater. Seus pais não faziam ameaças, e as críticas que eles faziam eram vistas por Rafael como construtivas e não como aversivas. Pode-se pressupor que os pais de Rafael (especialmente a mãe) eram bastante participativos por incentivarem e priorizarem o diálogo, além de considerarem os argumentos do filho (Baumrind, 1966).
No discurso de Paulo (Tabela 3), percebe-se que havia uma comunicação positiva com sua mãe, ou seja, conversava e perguntava coisas para ela sem muitas reservas. Porém ao observar o que Paulo relatou sobre seu pai, percebe-se o estabelecimento de uma comunicação muito negativa. O pai de Paulo fazia uso de palavrões, ameaças, e não tinha tolerância em ouvir o que seu filho tinha a dizer. Portanto, podese dizer que o pai de Paulo fazia uso de uma comunicação bastante coercitiva, a qual gerava medo e esquiva (como o próprio adolescente relatou). Percebe-se no relato de Paulo alguns dos efeitos colaterais de uma comunicação coercitiva (Sidman, 2001; Skinner, 1998).

\section{Punição}

Muitos aspectos interessantes sobre a punição surgiram no relato dos participantes: primeiramente, $\mathrm{o}$ 
tipo de punição (como os pais puniam); em segundo lugar, a consistência dos pais ao punir; e por último, os efeitos colaterais da punição. Estes aspectos podem ser observados nas frases da Tabela 4.

Tabela 4. Apresentação das frases relatadas por Rafael e Paulo, em relação ao tema punição

\begin{tabular}{|c|c|}
\hline Rafael & Paulo \\
\hline $\begin{array}{l}\text { 1- "Eu apanhei quando eu era criança, mas agora não. Só } \\
\text { discutir mesmo, falar alguma coisa. Só quando fazia alguma } \\
\text { coisa errada. Mas não bater de espancar, só davam umas } \\
\text { chineladas, só pra dar um aviso." } \\
\text { 2- "Nunca, de dar castigo, brigar porque eu não fiz alguma } \\
\text { coisa, eles nunca fizeram isso. Eles conversam ou dão al- } \\
\text { gum conselho." } \\
\text { 3- "Eles nunca descarregam em mim quando estão com pro- } \\
\text { blemas, só quando eles estão meio nervosos e às vezes eu } \\
\text { vou fazer alguma brincadeira, daí eles ficam meio bravos, } \\
\text { mas não por causa do problema deles." } \\
\text { 4- "Sempre que eles discutiam comigo era porque tinha algum } \\
\text { motivo." } \\
\text { 5- "Mas eu procurava me esconder, correr. Eu falava: não fui } \\
\text { eu, já estava assim. Ȧs vezes falava até alguma mentira, } \\
\text { mas depois ele descobria, e eu ficava de castigo do mesmo } \\
\text { jeito." } \\
\text { 6- "Antigamente eu tinha medo dele, eu pensava que ele estava } \\
\text { ruim, mas agora eu nem ligo muito. Não era por meio de } \\
\text { medo mas por respeito. Quando eu ia discutir com ele eu } \\
\text { pensava ele é meu pai, eu tinha que ficar quieto, que ele } \\
\text { estava certo." }\end{array}$ & $\begin{array}{l}\text { 1- "Meu pai batia na gente com aqueles 'rabo de tatu', sabe } \\
\text { aqueles de cavalo?" } \\
\text { 2- "Uma vez que eu falei para minha mãe que eu tinha ido com } \\
\text { ele na casa de uma mulher, ele me jogou de cabeça no bal- } \\
\text { de de alumínio." } \\
\text { 3- "Mas daí quando ele chegou, ele quase me afogou numa } \\
\text { baciazona que a minha mãe estava lavando roupa, quase } \\
\text { afogou eu no meio do sabão." } \\
\text { 4- "Eu queria explicar pro meu pai, mas ele já chegava baten- } \\
\text { do." } \\
\text { 5- "Minha mãe quase nunca brigou comigo, meu pai brigava. } \\
\text { (...) Um agradava e o outro batia." } \\
\text { 6- "A gente se comportava bem e via um dos irmãos apanhando } \\
\text { sem dever nada, é ruim." } \\
\text { 7- "Vou ter que mentir para ele não me bater. Daí fui aprenden- } \\
\text { do só mentir." } \\
\text { 8- "Por mais que ele batia na gente, eu gostava do meu pai, só } \\
\text { que eu fiquei traumatizado." }\end{array}$ \\
\hline
\end{tabular}

O primeiro aspecto a ser discutido é o tipo de punição utilizado pelos pais dos dois adolescentes. No relato de Rafael (frases 1 a 3 da Tabela 4), percebe-se que seus pais utilizavam punição física quando ele era criança, mas esta punição foi relatada pelo adolescente como algo com pouco significado, como um aviso. Rafael também relatou que seus pais pareciam preferir o diálogo ao invés dos castigos e broncas. Já no discurso de Paulo (frases de 1 a 4 da Tabela 4) foi possível perceber que seu pai fazia uso de punições extremamente severas, podendo ser consideradas até mesmo como mau-trato. É válido lembrar aqui que a exposição freqüente a punição pode trazer graves riscos e prejuízos ao desenvolvimento de crianças e adolescentes (Simons \& cols., 1998; Stormshak \& cols., 2000).

O segundo ponto importante a ser discutido é o da inconsistência. Percebe-se que os pais de Rafael apenas brigavam ou davam algum castigo quando realmente havia motivo para isso (frases 3 e 4, Tabela 4). Ao contrário dos pais de Rafael, os pais de Paulo pareciam não ser consistentes. Além de pai e mãe agirem de formas diferentes em relação a um comportamento do filho (frase 5), Paulo percebia as punições de seu pai de forma injusta e bastante exagerada.

O último e importante ponto a ser discutido é o que se refere aos efeitos colaterais da punição. $\mathrm{O}$ interes- sante é que os dois adolescentes relataram efeitos semelhantes: medo e esquiva (frases 5 e 6 de Rafael e 7 e 8 de Paulo). O contexto coercitivo (quer ele seja intenso e severo, quer ele seja mais brando) sempre gera subprodutos negativos tais como esquiva ou fuga, medo, raiva, sentimentos de fracasso, baixa autoestima e autoconfiança, violência, agressão, opressão, depressão, autodestruição e destruição dos demais, ódio, doenças e estado geral de infelicidade (Catania, 1999; Severe, 2000; Sidman, 2001; Skinner, 1998; Sousa \& Baptista, 2001). Deve-se considerar que estes subprodutos dependem também da freqüência e intensidade em que a coerção é utilizada. Portanto pode-se dizer que o contexto extremamente coercitivo em que Paulo foi criado é uma variável de grande relevância (não é a única, mas talvez a mais importante) na determinação de seus comportamentos anti-sociais. Além de tudo isso, como as pessoas que utilizam punições tornam-se elas próprias punidores condicionados, pode-se dizer que a simples presença do pai de Paulo poderia significar para ele uma punição (Sidman, 2001).

\section{Auto-estima}

A auto-estima foi um tema escolhido para discussão pelo fato de representar uma possível consequiência da educação que cada um dos adolescentes recebeu. $\mathrm{O}$ 
que eles relataram sobre a visão que possuem de si apresentados na Tabela 5. próprios, trouxe dados muito interessantes, que estão

Tabela 5. Apresentação das frases relatadas por Rafael e Paulo, em relação ao tema auto-estima

\begin{tabular}{c|l}
\hline Rafael & \multicolumn{1}{c}{ Paulo } \\
\hline $\begin{array}{c}\text { 1- "As pessoas desta instituição acham que eu sou alguém que } \\
\text { procura se esforçar e que tem vontade de aprender." }\end{array}$ & $\begin{array}{l}\text { 1- "As pessoas desta instituição acham que eu sou bandido." } \\
\text { 2- "Eu me acho um nada." } \\
\text { 2- "Eu me acho um cara bacana, eu sou legal com todo mundo." }\end{array}$ \\
\hline
\end{tabular}

Durante a entrevista realizada com os participantes, foi pedido a eles que completassem duas frases: "as pessoas desta instituição acham que eu sou..." e "eu me acho...". Observando a Tabela 5 (que apresenta as respostas destas questões), é possível perceber a nítida diferença entre a auto-estima dos dois participantes. Enquanto Rafael se considerava uma pessoa esforçada, bacana e legal, Paulo se via como bandido, como um nada. Pode-se discutir a hipótese de que a auto-estima destes adolescentes esteja relacionada com a educação que cada um recebeu, uma vez que vários autores demonstram que práticas ou estilos parentais afetam a auto-estima dos filhos (Parish \& McCluskey, 1992; Severe, 2000; Sidman, 2001; Webster-Stratton \& Herbert, 1994).

\section{Envolvimento com pares desviantes}

Este tema tem especial importância para a presente discussão, uma vez que este tipo de comportamento (envolvimento com pares desviantes) é o ponto mais marcante ao comparar diferenças comportamentais entre os dois jovens entrevistados. Ambos relataram ter contato com pares desviantes, porém Paulo se envolveu com eles e Rafael não. Na Tabela 6 é possível observar o que os adolescentes falaram a respeito disso, como também o que seus pais faziam em relação a isso.

Tabela 6. Apresentação das frases relatadas por Rafael e Paulo, em relação ao tema envolvimento com pares desviantes

\begin{tabular}{|c|c|}
\hline Rafael & Paulo \\
\hline $\begin{array}{l}\text { 1- "Lá eu sei que rola droga, já até me convidaram, os caras } \\
\text { falam numa boa. Quando eu vou jogar bola, a gente vê os } \\
\text { caras passando, a gente sabe que eles estão por ali." } \\
\text { 2- "Mas eu nunca aceitei. Eles não implicam, eles são bastante } \\
\text { amigos, assim, eles vão por vontade deles, eles não vão } \\
\text { obrigar a mim ou a qualquer outra pessoa a ir com eles." } \\
\text { 3- "Eles (os pais) ficam preocupados, por isso que eles ficam } \\
\text { ligando e perguntando, porque eu tenho amigos e às vezes } \\
\text { eu vou na casa desses amigos, só que eles moram mais } \\
\text { perto. E o meu pai fica preocupado porque eu estou próximo } \\
\text { daquele lugar." } \\
\text { 4- "Sentar pra conversar não, mas eles dão uns toques, falam: } \\
\text { não fique com aquele pessoal." } \\
\text { 5- "Eles dão conselho sobre amigo, com quem eu ando, ele } \\
\text { pode te envolver em alguma coisa, você pode entrar numa } \\
\text { pior." } \\
\text { 6- "Sair com alguém, às vezes quando eles (os pais) sabem } \\
\text { que aquela pessoa não tem uma boa imagem, eles não dei- } \\
\text { xam eu sair com ela porque eles acham que não é uma boa } \\
\text { coisa que eu vou estar fazendo. Eu não me sinto influencia- } \\
\text { do por aquela pessoa pra fazer alguma coisa, pelo menos eu } \\
\text { penso assim, não sei na hora, né, porque estar com uma } \\
\text { turma, de repente fica meio empolgado pra fazer coisa errada." }\end{array}$ & $\begin{array}{l}\text { 1- "Eu me envolvi. Dinheiro, tudo envolvido. Depois comecei a } \\
\text { usar droga, parei, consegui parar, daí eu caí preso." } \\
\text { 2- "É de seguir conselho dos outros que a gente fica preso." } \\
\text { 3- "Eu não vou mais morar perto daquela casa, lá perto de casa } \\
\text { onde eu estava morando com a minha mãe. Por causa das } \\
\text { amizades, né. Você sabe que se eu ficar ali, acaba voltando. } \\
\text { Se ficar desempregado, eles já vêm, e eu não quero isso." } \\
\text { 4- "Ah, ele (o pai) falava pra nós não se misturar com o pessoal, } \\
\text { pra não usar droga." } \\
\text { 5- "Ele (o pai) obrigou eles (os irmãos) a trabalhar. Obrigou não, } \\
\text { falou: é melhor vocês irem trabalhar do que ficar aí com es- } \\
\text { ses vagabundos." } \\
\text { 6- "Ele falava que não gostava que a gente andasse com mau } \\
\text { companhia aqui na rua, ele se arrependeu no último, que ele } \\
\text { batia em nós para a gente não se envolver. De repente ba- } \\
\text { teu, bateu e acabamos se envolvendo. Se não batesse acho } \\
\text { que a gente não se envolvia." }\end{array}$ \\
\hline
\end{tabular}

Primeiramente é possível observar como cada um dos adolescentes se comportou diante de um grupo desviante (principalmente com consumo e venda de drogas). Rafael falou explicitamente que já teve contato com estas pessoas e que inclusive já foi convidado a participar das atividades deste grupo. Mas a sua 
atitude foi de recusa. Enquanto que Paulo falou diretamente ter se envolvido com um grupo desviante (o qual também fazia roubo de carros) por causa de dinheiro. O dinheiro, neste caso, é um potente reforçador, uma vez que através de um emprego dificilmente Paulo ganharia tanto quanto ganhava com o roubo de carros. Paulo relatou também que agora prefere ficar longe destas pessoas, para não se sentir mais influenciado.

Em segundo lugar, também foi possível observar nos relatos, quais as atitudes tomadas pelos pais dos adolescentes em relação aos grupos desviantes. Os pais de Rafael pareciam fazer grande uso de monitoria (ligar, perguntar) e conselhos (frases 3 a 6, Tabela 6). Por outro lado, os pais de Paulo, especialmente o pai, fazia mais uso de coerção: obrigava a trabalhar e punia fisicamente (frases 4 a 6, Tabela 6). Porém o que pai de Paulo fazia, provavelmente sem ter consciência disso, era uma grande contradição, pois como a coerção gera esquiva, seu pai o ensinou a se afastar e a procurar aceitação e reforços positivos em outro ambiente ou grupo. Ao invés de impedir, o pai de Paulo provavelmente propiciou situações para que isto ocorresse. Vale lembrar que além das práticas coercitivas estarem vinculadas ao comportamento de esquiva, Simons e cols. (1998) demonstraram que o baixo apoio e envolvimento dos pais (como o pai de Paulo) foram associados com delinqüência e uso de drogas na adolescência.

\section{CONSIDERAÇÕES FINAIS}

Levando-se em consideração os princípios da Análise do Comportamento, principalmente o de condicionamento operante, bem como todo o conhecimento acerca das práticas parentais, é possível levantar a hipótese de que os comportamentos pró-sociais de Rafael e os anti-sociais de Paulo foram modelados e condicionados, em grande parte, a partir da relação com seus pais.

Ao fazer uma breve análise global das contingências que atuavam sobre o comportamento de Rafael, foi possível perceber que a maior parte do controle que seus pais exerciam incluía reforçamento positivo de comportamentos adequados e socialmente adaptados. Conseguiam, na maior parte do tempo, manter uma comunicação positiva, regras bem definidas e conseqüências coerentes e justas. De forma geral, pode-se dizer que os pais de Rafael utilizavam-se, na maior parte do tempo, de controle não-coercitivo. Desta forma, conseguiam ensinar o cumprimento de regras, responsabilidade, auto-estima, comportamentos pró-sociais, afeto, diálogo, entre outros (Baumrind, 1966; Bee, 1996; Cavell, 2000; Gomes, 1981; Matos, 2001; Patterson \& Gullion, 1968; Patterson \& Stouthammer-Loeber, 1984; Severe, 2000; Sidman, 2001; Sousa \& Baptista, 2001; Webster-Stratton \& Herbert, 1994).

Quanto à família de Paulo, a análise realizada apresenta justamente o oposto: controle coercitivo. O discurso de Paulo trouxe à tona os perigos do controle coercitivo, ou seja, ele descreveu as práticas aversivas utilizadas por seus pais (principalmente seu pai), e o que ele aprendeu e ganhou com este tipo de educação. Falta de afeto, regras e monitoria deficientes, reforçamento de comportamentos inadequados, comunicação ausente ou negativa, punições exageradas (classificadas até mesmo como mau-trato) e modelo de comportamento agressivo são condições propícias para criar um adolescente com tais características. É claro que o comportamento anti-social de Paulo pode ter sido influenciado também por outras variáveis que aqui não estão sendo discutidas, portanto a sua educação não determinou a pessoa que ele era, mas certamente influenciou muito. Vários de seus comportamentos (baixa auto-estima, fracasso escolar, delinqüência, envolvimento com drogas, e outros comportamentos anti-sociais) são apontados por vários autores como sendo conseqüência de uma educação falha e/ou coercitiva (Castanheira, 2001; Catania, 1999; Chen \& cols., 2002; Severe, 2000; Sidman, 2001; Simons \& cols., 1998; Skinner, 1998; Sousa \& Baptista, 2001; Stormshak \& cols., 2000; Weber \& cols., 2003b).

Reppold, Pacheco, Bardagi e Hutz (2002, p. 10) alertam sobre os fatores de risco para o desenvolvimento de uma criança, estes "são condições ou variáveis que estão associadas a uma alta probabilidade de ocorrência de resultados negativos ou indesejáveis". Oliveira (1998) afirma que dentre os diversos mecanismos de risco familiar, estão principalmente os estilos e práticas parentais prejudiciais à socialização da criança (como violência), eventos familiares estressantes (como conflitos conjugais), psicopatologia materna ou paterna (como personalidade anti-social) e falta de apoio social à família. De acordo com estas definições é possível dizer que Paulo viveu por muitos anos em um ambiente de risco para o seu desenvolvimento, e "quando os eventos estressantes pesam mais que os fatores de proteção, até a criança mais resiliente pode ter problemas" (Oliveira, 1998, p. 21).

Considerando a revisão teórica deste trabalho, os princípios da aprendizagem social e as análises realizadas com os adolescentes desta pesquisa, pode-se 
defender o quanto fundamental é o papel dos pais no processo de aprendizagem e socialização de seus filhos. Porém "as pessoas tornam-se pais sem que ninguém as tenha ensinado como dar conta desta responsabilidade" (Sidman, 2001, p. 250). É por isso que muitos pais agem em função dos modelos recebidos durante a vida, sem questionar ou aprender sobre a melhor forma de educar. E assim, muitos pais se engajam em relacionamentos problemáticos com seus filhos, podendo gerar graves problemas de comportamento para estes últimos.

É neste contexto que o estudo das práticas parentais vem sendo reconhecido como importante estratégia preventiva para problemas comportamentais na infância (Rocha, 2003). Talvez a divulgação deste tipo de conhecimento para pais seja o caminho mais fácil e curto para prevenção do uso de drogas, delinquiência, problemas e distúrbios comportamentais, psicológicos e cognitivos, fracasso escolar, depressão, stress, entre outros. Os profissionais da área da Psicologia devem estar atentos para este tipo de trabalho que focaliza a família e não somente a "criança/adolescente problema”. Há um vasto campo a ser cultivado quando se fala em psicologia preventiva, e a informação aos pais (seja através de treinamento de pais, terapia familiar, ou até mesmo palestras e livros ilustrativos) pode ser o melhor caminho para que as crianças de hoje não se tornem adolescentes e adultos "problemáticos".

\section{REFERÊNCIAS}

Alvarenga, P. (2001). Práticas educativas parentais como forma de prevenção de problemas de comportamento. Em H. J. Guilhardi (Org.), Sobre Comportamento e Cognição, v. 8, (pp. 54-60). Santo André: ESETec Editores Associados.

Baumrind, D. (1966). Effects of authoritative control on child behavior. Child Development, 37, 887-907.

Belsky, J., Hsieh, K. \& Crnic, K. (1998). Mothering, fathering, and infant negativity as antecedents of boys' externalizing problems and inhibition at age 3 years: differential susceptibility to rearing experience? Development and Psychopathology, 10, 301-319.

Castanheira, S. S. (2001). Regras e aprendizagem por contingência: sempre e em todo lugar. Em H. J. Guuilhardi (Org.), Sobre o Comportamento e Cognição, v. 7 (pp. 36-46). Santo André, SP: ESETec Editores Associados.

Catania, A. C. (1999). Aprendizagem: comportamento, linguagem e cognição ( $4^{\mathrm{a}}$ ed.). Porto Alegre: Artmed Editora.

Cavell, T. A. (2000). Working with parents of aggressive children: a practitioner's guide. Washington DC: American Psychological Association.

Chen, H., Chen, X., Liu, M. \& Wang, L. (2002). Noncompliance and child-rearing attitude as predictors of aggressive behavior: a longitudinal study in chinese children. International Journal of Behavioral Development, 26(3), 225-233.
Dishion, T. J., Patterson, G. R., Stoolmiller, G. \& Skinner, M. L. (1991). Family, school, and behavioral antecedents to early adolescent involvement with antisocial peers. Developmental Psychology, 27, 172-180.

Gomes, M. J. C. (1981). Efeitos de um sistema de reforçamento por fichas na execução de tarefas domésticas. Didática, 17, 99106.

Grusec, J. E., Goodnow, J. J. \& Kuczynski, L. (2000). New directions in analysis of parenting contributions to children's acquisition of values. Child Development, 71(1), 205-211.

Kafka, R. \& London, P. (1991). Communication in relationships and adolescent substance use: the influence of parents and friends. Adolescence, 26(103), 587-598.

Kaplow, J. B., Curran, P. J. \& Dodge, K. A. (2002). Child, parent, and peer predictors of early-onset substance use: a multisite longitudinal study. Journal of Abnormal Child Psychology. Obtido em 18 de março de 2004 doo Findarticles no Word Wide Web: http://www.findarticles.com/cf_dls/m0902/3_30/ 86874928/p1/article.jhtml.

Kelly, K. J., Comello, M. L. G. \& Hunn, L. C. P. (2002). Parentchild communication, perceived sanctions against drug use, and youth drug involvement. Adolescence. Obtido em 18 de março de 2004 do Word Wide Web: http://www. findarticles. com/cf_O/m2248/148_37/97723212/pl/article.jhtml.

Kochanska, G. \& Aksan, N. (1995). Mother-child mutually positive affect, the quality of child compliance to requests and prohibitions, and maternal control as correlates of early internalization. Child Development, 66, 236-254.

Krevans, J. \& Gibbs, J. C. (1996). Parents' use of inductive discipline: relations to children's empathy and prosocial behavior. Child Development, 67, 3263-3277.

Matos, M. A. (2001). Comportamento governado por regras. Revista Brasileira de Terapia Comportamental e Cognitiva, 3(2), 51-66.

Oliveira, E. A. (1998). Modelos de risco na psicologia do desenvolvimento. Psicologia: Teoria e Pesquisa, 14(1), 19-26.

Parish, T. S. \& McCluskey, J. J. (1992). The relationship between parenting stiles and young adult's self-conceps and evaluation of parents. Adolescence, 27, 915-918.

Patterson, G. R. \& Gullion, M. E. (1968). Convivendo com as crianças. Coordenada Editora de Brasília.

Patterson, G. R. \& Stouthammer-Loeber, M. (1984). The correlation of family management practices and delinquency. Child Development, 55, 1299-1307.

Reid, J. B., Patterson, G. R. \& Snyder, J. (2002). Antisocial behavior in children and adolescents. Washington D.C.: American Psychological Association.

Reppold, C. T, Pacheco, J., Bardagi, M. \& Hutz, C. S. (2002). Prevenção de problemas de comportamento e desenvolvimento de competências psicossociais em crianças e adolescentes: uma análise das práticas educativas e dos estilos parentais. Em C. S. Hutz (Org.), Situações de risco e vulnerabilidade na infância e adolescência: aspectos teóricos e estratégias de intervenção (pp. 9-51). São Paulo: Casa do Psicólogo.

Schaffer, H. R. \& Crook, C. K. (1980). Child compliance and control techniques. Developmental Psychology, 16, 54-61.

Severe, S. (2000). A educação pelo bom exemplo. Rio de Janeiro: Campus.

Interação em Psicologia, Curitiba, jul./dez. 2005, (9)2, p. 341-353 
Sidman, M. (2001). Coerção e suas implicações. Campinas: Editora Livro Pleno.

Simons, R. L, Lin, K. H. \& Gordon, L. C. (1998). Socialization in the family of origin and male dating violence: a prospective study. Journal of Marriage and the Family, 60 (2), 467-478.

Skinner, B. F. (1991). Questões recentes na análise comportamental. Campinas, SP: Papirus.

Skinner, B. F. (1998). Ciência e comportamento humano (10 $\left.10^{\mathrm{a}} \mathrm{ed}.\right)$. São Paulo: EDART - São Paulo Livraria Editora Ltda.

Sousa, C. R. \& Baptista, C.P. (2001). Terapia cognitivocomportamental com crianças. Em B. Rangé (Org.), Psicoterapias cognitivo-comportamentais: um diálogo com a psiquiatria. Porto Alegre: Artmed Editora.

Stormshak, E. A., Bierman, K. L., Mcmahon, R. J. \& Lengua, L. J. (2000). Parenting practices and child disruptive behavior problems in early elementary school. Journal of Clinical Child Psychology, 29(1), 17-29.

Todorov, J. C. (2001). Quem tem medo de punição? Revista Brasileira de Terapia Comportamental e Cognitiva, 3(1), 37-40.
Weber, L. N. D. (2005). Eduque com carinho. Curitiba: Juruá.

Weber, L. N. D., Viezzer, A. P. \& Brandenburg, O. J. (2003a). Validação do instrumento EQIF (Escalas de Qualidade de Interação Familiar). Em Associação Brasileira de Psicoterapia e Medicina Comportamental (Org.), Anais do XII Encontro Brasileiro de Psicoterapia e Medicina Comportamental (pp. 276-277). Londrina: ABPMC.

Weber, L. N. D., Viezzer, A. P., Brandenburg, O. J. (2003b). Estilos parentais e desenvolvimento da criança e do adolescente. Palmadas e surras: ontem, hoje e amanhã. Em M. Z. Brandão, F. C. S. Conte, F. S. Brandão,Y. K. Ingberman, C. B. Moura, V. M. Silva, S. M. Oliane (Org.), Sobre o comportamento e cognição, v. 11. (pp. 499-511). Santo André: ESETec Editores Associados.

Webster-Strtratton, C. \& Herbert, M. (1994). Troubled families problem children: Working with parents: a collaborative process. John Wiley \& Sons, NY.

Recebido: 20/07/2005

Revisado: 10/12/2005

Aceito: 15/12/2005

\section{Notas:}

${ }^{1}$ O presente artigo é uma parte da monografia de conclusão de Curso de Psicologia da primeira autora, orientada pela segunda autora.

${ }^{2}$ Programa não-governamental que seleciona alunos do ensino fundamental, com baixo nível socioeconômico, que possuem excelente desempenho acadêmico (notas acima de 7,0), e com grande interesse e comprometimento com os estudos. Este programa financia todos os seus estudos em escolas particulares, até a pós-gradução.

${ }^{3}$ Serviço de Atendimento Social, vinculado à delegacia de adolescentes, no qual os adolescentes ficam detidos à espera de julgamento.

\section{Sobre as autoras:}

Ana Paula Viezzer Salvador: Psicóloga e mestranda do Programa de Pós-Graduação em Educação da UFPR.

Lidia Natalia Dobrianskyj Weber: Professora do Departamento de Psicologia e do Programa de Pós-Graduação em Educação da UFPR; Mestra e Doutora em Psicologia Experimental pela USP.

Endereço para correspondência: UFPR - Departamento de Psicologia - Pç. Santos Andrade, 50/1 - 80060-000 Curitiba-PR.: (lidiaw@uol.com.br) 